\title{
Inteligência Artificial e formação danificada: aprendizagem profunda e ética rasa entre professores e alunos ${ }^{1}$
}

\section{Artificial Intelligence and semi-formation: deep learning and shallow ethics among teachers and students}

\author{
Antônio A. S. Zuin*
}

\begin{abstract}
RESUMO
Em tempos de conexão ininterrupta, consolida-se o denominado capitalismo de vigilância. Nesse estágio do modo de produção capitalista, o capital é produzido e reproduzido por meio do controle dos grandes dados (big data), que são obtidos através dos dispositivos de vigilância presentes tanto nos softwares algorítmicos, quanto nas câmeras de reconhecimento facial. Nesse contexto, insere-se o objetivo deste artigo: refletir sobre a forma como a utilização de dispositivos de decisão diretiva (directive decision devices), fundamentados nos princípios da Inteligência Artificial (IA), pode fazer com que um sistema de vigilância prevaleça entre professores e alunos, em detrimento de relações eticamente elaboradas entre ambos. Concluise que a chamada aprendizagem profunda, algoritmicamente produzida, deve ser repensada nos termos da revitalização da formação (Bildung), que questiona a pretensão de tal aprendizagem fomentar procedimentos éticos entre professores e alunos pautados num sistema de premiação e punição decorrente da vigilância digital ubíqua.
\end{abstract}

Palavras-chave: Inteligência Artificial. Teoria Crítica. Adorno. Ética. Aprendizagem profunda.

1 A elaboração deste artigo foi possível por meio dos recursos de pesquisa obtidos junto ao Conselho Nacional de Desenvolvimento Científico e Tecnológico (CNPq), bolsista produtividade em pesquisa e Programa Institucional de Internacionalização da Coordenação de Aperfeiçoamento de Pessoal de Nível Superior (/PRINT/CAPES). Estágio pós-doutoral na Universidade J. W. Goethe, Frankfurt am Main, Alemanha, 2020).

" Universidade Federal de São Carlos. Programa de Pós-Graduação em Educação. São Carlos, São Paulo. Brasil. E-mail: dazu@ufscar.br - https://orcid.org/0000-0002-6850-2897 


\begin{abstract}
In times of uninterrupted connection, the so-called surveillance capitalism has been consolidated. At this stage of the capitalist mode of production, capital is produced and reproduced through the control of big data, which is obtained through the surveillance devices present in both algorithmic software and facial recognition cameras. In this context, the authors elaborated the following objective: to reflect on how the use of directive decision devices, based on the principles of Artificial Intelligence (AI), can make a surveillance system prevail between teachers and students, to the detriment of ethically developed relationships between them. We concluded that the so-called deep learning, which is algorithmically produced, must be rethought in terms of the revitalization of formation (Bildung), which questions the intention of such learning to foster ethical procedures between teachers and students based on a system of reward and punishment resulting from digital ubiquitous surveillance.
\end{abstract}

Keywords: Artificial Intelligence. Critical Theory. Adorno. Ethics. Deep learning.

\title{
Introdução
}

As grandes obras de ficção científica parecem estar se tornando cada vez mais raras na sociedade da cultura digital. A intensidade da narrativa futurística de um livro, tal como "Admirável mundo novo" (HUXLEY, 1969), publicado originariamente em 1932, está se tornando difícil de ser observada, talvez pelo fato de que a velocidade do desenvolvimento tecnológico está abreviando as diferenças espaçotemporais existentes entre a ficção e a realidade de forma inaudita. Um exemplo notório desta abreviação se faz presente no modo como o que fora previsto no conto de Philip Dick (1928-1982), intitulado “Minority report" (DICK, 2018), se materializa na sociedade da cultura digital. Transformado em filme por Steven Spielberg em 2002, o conto de Dick descreve uma sociedade futurista na qual policiais manipulam digitalmente imagens advindas de telepatas. Quando os policiais selecionam as imagens-pensamento dos telepatas e as projetam nas telas, torna-se possível antever situações relacionadas ao cometimento de crimes, tais como assassinatos e estupros.

O livro de Dick foi publicado em 1956. Já em 2008, iniciou-se a produção da plataforma Hunchlab, desenvolvida primeiramente pela empresa Azavea, com o objetivo de se tornar um sistema de gerenciamento de patrulhas policiais. Mas não se trata de um gerenciamento qualquer, pois tem-se o propósito de, 
por meio da utilização de tal plataforma, prever quando e como um crime será cometido. Fundamentando-se na análise de dados sobre crimes já praticados, principalmente por meio da utilização de modelos preditivos, o "sistema indica a probabilidade de ocorrer incidentes criminais em determinados locais e horários específicos" (KAUFMAN, 2019, p. 53).

No lugar dos telepatas imaginados por Philip Dick, são os algoritmos da plataforma Hunchlab que, ao serem acionados, relacionam as variáveis sobre os crimes cometidos, tais como sazonalidade, condições socioeconômicas, dia da semana, hora do dia. Com base em tais dados algoritmicamente calculados, essa plataforma envia as informações aos policiais, prevendo assim a realização de determinados crimes, bem como os indicadores de risco concernentes a cada um deles. A utilização destes algoritmos se insere no campo da cultura digital contemporânea, na qual as influências da denominada Inteligência Artificial (IA), da aprendizagem de máquina (Machine learning) e da aprendizagem profunda (Deep learning) tendem a se materializar nas mais variadas atividades das relações de trabalho e do denominado tempo livre, cujas fronteiras são cada vez mais arrefecidas.

Desde a já mencionada utilização dos algoritmos da plataforma Hunchlab para a previsão de futuros crimes, passando pelo uso de tal tecnologia para a previsão e seleção algoritmicamente calculada de músicas feita pelo Spotify, ou de filmes e séries pelo Netflix, ampliam-se cada vez mais não somente o acesso a uma quantidade praticamente infinita de dados, como também a presença de um tipo de vigilância e de controle maquinal inédito em relação às ideias e comportamentos das pessoas. Evidentemente a esfera da educação não poderia deixar de ser influenciada pelo modo como os princípios da IA maquinalmente determinam uma espécie de reconfiguração da relação professoraluno, fundamentada na consolidação da aprendizagem profunda. Face a esse contexto, caberiam as seguintes perguntas: a) Qual seria o significado da expressão "aprendizagem profunda" na sociedade cujos imensos volumes de dados (big data) são algoritmicamente selecionados, classificados e consumidos cotidianamente?; b) Quais seriam as consequências no processo formativo em virtude da expansão cada vez maior da aprendizagem profunda? c) De que modo as relações entre professores e alunos seriam reconfiguradas em decorrência da consolidação da aprendizagem profunda nas atividades estabelecidas entre ambos os grupos dentro e fora das escolas? São questões como essas que estimularam a elaboração deste artigo com o seguinte objetivo: refletir sobre a forma como a utilização de dispositivos de decisão diretiva (directive decision devices), amparados nos princípios da IA, pode fazer com que um sistema de vigilância, pautado pela premiação e punição, prevaleça entre professores e alunos em detrimento de relações eticamente elaboradas entre eles. 
Porém, antes de apresentar as ponderações referentes aos princípios da IA e da aprendizagem profunda, é preciso refletir sobre um momento histórico crucial sobre a utilização de máquinas cujos princípios de ensino e aprendizagem foram delineados em aplicações de recompensas e punições: a chamada máquina de ensinar, tal como foi destacado por Burrhus Frederic Skinner na década de 1960.

\section{Vigilância, recompensa e punição: as máquinas de ensinar nas salas de aula}

O fascínio do ser humano pelas máquinas sempre pôde ser historicamente observado. Porém, na medida em que estas mesmas máquinas gradativamente passaram a estar presentes em praticamente todas as relações humanas, sobretudo com a consolidação da Revolução Industrial, engendraram-se condições para que novos parâmetros de comparação fossem desenvolvidos. Günther Anders (1902-1992) elaborou um conceito que descreve, de forma precisa, as características de tal comparação entre humanos e máquinas: a chamada vergonha prometeica, que remete imediatamente à lembrança do mito de Prometeu.

Ao roubar o fogo e entregá-lo aos seres humanos, Prometeu foi severamente punido pelos deuses olímpicos justamente porque os humanos se deificaram, por assim dizer, de modo que os próprios deuses deixaram de ser tão importantes quanto à determinação do destino da humanidade. A admiração que a humanidade sentiu diante do poder do fogo e, principalmente, a possibilidade de dominar a técnica de sua produção, paradoxalmente, suscitaram o aparecimento do sentimento de vergonha decorrente do fato de que se tornou claro o quão frágil a carne se revelou diante do poderio do fogo. E se o fogo pudesse ser substituído pelas máquinas, então o sentimento de vergonha seria ainda mais intensificado, pois o ser humano se tornaria profundamente incomodado em "apresentar, diante dos olhos dos aparelhos perfeitos, sua patética condição de ser carnal, a imprecisão de sua condição humana. Na verdade, ele tinha mesmo que se envergonhar diante disso" (ANDERS, 2002, p. 23, tradução nossa).

É interessante observar que, historicamente, a vergonha foi caracterizada como um sentimento de conotação moral de grande relevância para o desenvolvimento psíquico e, portanto, para a própria personalidade. Frente à constatação, muitas vezes dolorosa, de que ainda não compreendia os significados dos conceitos apresentados pelos adultos, a criança envergonhada se sensibilizava a realizar a autocrítica necessária para se autodisciplinar e, portanto, 
se esforçar para gradativamente aprender e dominar tal aparato conceitual que seria, a princípio, controlado pelos adultos. Porém, se tal sentimento de vergonha proporciona a autocrítica de que ainda não se estava preparado para o entendimento dos assuntos que orbitam o chamado mundo dos adultos e que, portanto, deveria se esforçar para fazê-lo, já a vergonha que o indivíduo sente quando compara suas debilidades física e mental com a exuberância do poder maquinal o impele não para a efetivação de tal autocrítica, mas sim para a ânsia de se assemelhar cada vez mais às máquinas. Por certo, "máquina alguma se deixa manipular sem que seus operadores acabem se equiparando a seu programa, a seu movimento" (TÜRCKE, 2016, p. 28).

Ao realizar a pesquisa sobre o processo de desenvolvimento da chamada personalidade autoritária, Adorno (1903-1969) e sua equipe de pesquisadores observaram o modo como esse desejo de ser máquina caracterizou a elaboração de uma ontologia completamente afeita ao espírito objetivo de uma época marcada pelo apogeu da Revolução Técnico-Científica. Assim, já na década de 1940, um dos entrevistados da pesquisa sobre os fundamentos psicossociais da personalidade autoritária dizia ter uma boa autoestima, pois gostava de belos equipamentos (ADORNO, 1972).

É no contexto do auge da Revolução Técnico-Científica que o desejo de ser máquina se espraia para todas as relações sociais, de modo que, justamente nesse período histórico, o ethos maquinal torna-se cada vez mais onipresente, inclusive nas relações entre professores e alunos estabelecidas no transcorrer dos processos de ensino e aprendizagem. Com efeito, no livro de sugestivo título, "Tecnologia do ensino", publicado no final da década de 1960, Burrhus Frederic Skinner (1904-1990) já enaltecia a relevância da chamada máquina de ensinar, que era assim por ele descrita:

O aparelho consiste numa caixa de tamanho aproximado de um gravador. $\mathrm{Na}$ parte superior há uma abertura, através da qual pode ser visto um problema ou uma questão impressos numa fita de papel. A criança responde movendo um ou mais dos cursores sobre os quais estão impressos os dígitos de 0 a 9 . A resposta aparece em furos quadrados picotados no mesmo papel em que está impressa a pergunta. Uma vez que a resposta tenha sido marcada, a criança gira um botão [...]. Se a resposta estiver certa, o botão gira com facilidade e pode ser adaptado para fazer piscar uma luz ou fazer funcionar algum outro reforçador condicionado. Se a resposta estiver errada, o botão não gira. $\mathrm{O}$ aparelho pode vir com um contador que marque as respostas erradas em cada série de passos (SKINNER, 1972, p. 21). 
De acordo com Skinner, o aprendizado decorrente da utilização da máquina de ensinar seria muito mais eficiente, sobretudo em função do fato de que os comportamentos dos alunos seriam imediatamente reforçados, caso acertassem a resposta de uma determinada questão. Além disso, os ritmos de cada um dos alunos seriam respeitados, uma vez que a passagem da resposta de uma questão para outra dependeria do entendimento de cada um deles em relação aos conteúdos ensinados pelas professoras e professores. Frente a essa proposta, seria relevante enfatizar o modo como Skinner aparta as dimensões cognitiva e ético-afetiva afeitas ao aprendizado de tais conteúdos por parte das alunas e alunos.

Por um lado, Skinner afirma categoricamente que as máquinas são muito mais abalizadas a, digamos, gerenciar as contingências de controle dos organismos do que os próprios seres humanos, pois o comportamento de um ser humano "pode ser afetado por detalhes sutis, que estão além da capacidade do organismo humano para arranjar [...] o fato puro e simples é que, na qualidade de mero mecanismo reforçador, a professora está fora de moda" (SKINNER, 1972, p. 20). Por outro lado, se diante do poderio da máquina de ensinar a professora estaria fora de moda - na condição de administradora das contingências de controle dos comportamentos dos alunos referentes ao aprendizado dos conteúdos de leitura, escrita, ortografia e aritmética, entre outros -, ela poderia ter mais tempo para estabelecer com os alunos "contatos intelectuais, culturais e emocionais daquele tipo todo especial que testemunha a sua natureza de ser humano" (SKINNER, 1972, p. 25). Deste modo, o processo de ensino e aprendizagem de conteúdos estaria a cargo das máquinas de ensinar, haja vista que a professora poderia, ao se ver livre de tal processo, focar sua atenção para outros empreendimentos mais condizentes à sua condição de ser humano, pois ela jamais teria as habilidades necessárias para poder competir com o poderio maquinal. Embora Skinner não tenha feito uso do conceito de Anders em seus escritos, poder-se-ia asseverar que a professora teria que se envergonhar prometeicamente de sua falibilidade humana e reconhecer que nunca teria condições de rivalizar com a máquina de ensinar. Além disso, teria também que admitir que seria muito mais eficaz caso se limitasse a lidar com tópicos das dimensões intelectual, cultural e emocional nas relações estabelecidas com o corpo discente.

Além de uma provável misoginia presente na caracterização da professora (por que ela?), tomada como ineficiente frente à máquina de ensinar, esta cisão entre o aprendizado de conteúdos e a esfera ético-afetiva ilustra muito bem a forma como a razão, materializada nas relações entre professores e alunos, se instrumentaliza nos ambientes escolares já em meados do século XX, de modo a fomentar a prevalência tecnológica dos meios sobre os fins. Não há como negar 
a complexidade do raciocínio de Skinner em relação à procura de meios para consolidar eficazmente o aprendizado das alunas e alunos sobre os conteúdos aprendidos. Para que se tenha uma ideia deste fato, basta mencionar que, antes mesmo que os computadores se disseminassem onipresentemente para todas as relações sociais, Skinner observou que seria preciso desenvolver máquinas de ensinar que fossem aptas a avaliar as composições das respostas das alunas e alunos, ao invés delas se limitarem a questões de múltipla escolha.

Ao lado do reconhecimento da complexidade analítico-administrativa da máquina de ensinar, há que se enfatizar também a pretensão skinneriana da existência da neutralidade nas relações de ensino e aprendizagem. E mais: diante da suposta falibilidade dos julgamentos de valores das educadoras e educadores, haveria melhor instrumento para garantir tal neutralidade do que a própria máquina de ensinar? Ou seja, além do fato, nas palavras de Skinner (1972, p. 55), de a máquina ter "uma paciência infinita" no trato com os alunos, não haveria mais o risco do aprendizado dos conteúdos de todas as matérias ensinadas nas salas de aula ficar à mercê dos juízos de valores das professoras e dos professores. Por meio da utilização das máquinas de ensinar, esses conteúdos poderiam ser completamente desassociados das avaliações morais das educadoras e educadores, evitando-se assim que tais conteúdos fossem relacionados, segundo Skinner (1972, p. 17), às "proposições vagas: educar para a democracia, educar a criança como um todo, educar para a vida, e assim por diante". Ainda, de acordo com Skinner (1972, p. 18), "infelizmente, estas filosofias não sugerem, por sua vez, melhorias nas técnicas. Oferecem pouca ou nenhuma ajuda no planejamento de melhores práticas nas classes".

A caracterização de Skinner da expressão "educar para a democracia" como uma proposição vaga desvela o entendimento reificado de que o educar deve ser circunscrito ao aprendizado dos conteúdos das matérias, de tal maneira que refletir historicamente sobre a relação entre o conceito de democracia e esses conteúdos não deveria se fazer presente no transcorrer do cotidiano das práticas escolares. Justamente por ser caracterizada como uma proposição vaga, o ensino seria muito mais produtivo caso fosse focado na aquisição de habilidades tais como "escrever ou calcular rápido" (SKINNER, 1972, p. 17).

É interessante destacar que a pretensão da supremacia da neutralidade quanto à aquisição de tais habilidades, que aparentemente se fundamenta num processo de ensino e aprendizagem empiricamente orquestrado, revelase, filosoficamente, como uma espécie de pretensão absoluta, como se tais habilidades pudessem ser identificadas como algo em si e por si, completamente separadas das mediações históricas que as engendraram. Pois, será que os atos de escrever e calcular rapidamente permanecem os mesmos, a despeito dos diferentes contextos históricos, sociais e culturais nos quais foram e são 
efetuados? E mais: será que tais atos, como produtos das relações humanas que são, não portariam imanentemente os juízos de valores já presentes nos atos de suas concepções?

Ao que tudo indica, o sortilégio que as máquinas exercem sobre seus próprios produtores, sobretudo a partir da Revolução Industrial, fomentou a disseminação de uma concepção espaçotemporal reificada, à medida que a própria tecnologia deixa de ser considerada como modus vivendi, produzida, portanto, por determinados processos sociais, e se restringe a ser caracterizada como um conjunto de técnicas agrupadas para a realização de um objetivo. Adorno observou que, quanto mais as pessoas são transformadas em coisas, mais elas projetam nessas mesmas coisas uma espécie de aura humana, de tal forma que a "libidinização das bugigangas é indiretamente narcísica, na medida em que alimenta o controle da natureza pelo ego: esses aparelhos proporcionam ao sujeito lembranças de sentimentos primitivos de onipotência" (ADORNO, 2008, p. 102-103).

Certamente, a pretensão de se usar a máquina de ensinar para gerenciar e controlar as contingências comportamentais dos alunos proporciona a fruição do sentimento de onipotência derivado de uma espécie de identificação com o poder maquinal. É por isso que a possibilidade de discussão dos conceitos como democracia, no transcorrer das práticas escolares, é identificada como uma proposição vaga e, portanto, ineficaz, pois produz um tipo de perda de tempo que obstaculiza o desenvolvimento das habilidades técnicas concernentes a escrever e calcular rapidamente. É também por isso que é libidinalmente atribuída à própria máquina de ensinar a característica de possuir uma paciência infinita, sendo que a infinitude da paciência maquinal contrasta com a finitude da fleuma das educadoras e educadores humanos.

Mas mesmo o narcisismo daquele que se identifica com os atributos maquinais não consegue eclipsar o fato de que tal sentimento de onipotência é, na realidade, uma cifra da própria impotência de não poder assumir o que se pensa diante dos alunos sobre os mais variados assuntos, haja vista que isso poderia atrapalhar o aprendizado dos conteúdos maquinalmente apresentados ao corpo discente.

Seguindo essa linha de raciocínio, não por acaso Skinner reflete sobre a presença da ética em sala de aula em termos da aplicação de técnicas de reforço de determinados comportamentos dos alunos. É interessante enfatizar a lembrança das palavras de Aristóteles, feita por Skinner (1972), no subitem "Autocontrole ético" de seu livro "Tecnologia do ensino". Ao mencionar a relevância de se estimular a concretização do autocontrole ético por parte do aluno, Skinner lembra as ponderações do filósofo estagirita de que só nos tornamos justos ou pessoas moderadas quando praticamos atos justos e 
moderados (ARISTÓTELES, 1991). Ou seja, é por meio da realização de tais atos que as pessoas podem ser designadas como portadoras de determinadas características comportamentais. Embora concorde com essa assertiva de Aristóteles (384-322 a.C.), Skinner observa que o difícil é controlar as contingências das realizações de tais atos. Contudo, isso seria possível por meio do emprego do método de aprendizagem pautado na aplicação de reforços, que aumentariam, ou não, a probabilidade de que comportamentos específicos dos alunos pudessem ocorrer novamente em situações semelhantes.

Assim, dependendo das consequências de certas ações dos alunos, as quais seriam previamente reforçadas pelo professor, essas mesmas ações do corpo discente poderiam não somente retornar em situações futuras, como também estimular a realização do autocontrole, inclusive ético, do aluno. De acordo com essa lógica de aplicação de reforços comportamentais, de modo a condicionar comportamentos operantes considerados éticos, Skinner assevera o seguinte:

O mérito pessoal é uma questão crucial no autogoverno ético. O estudante não acumula méritos quando se comporta bem se a ocasião não permite que se comporte mal. Quando se comporta bem porque aprendeu a fazêlo, reposta por resposta, os méritos vão quase todos para o professor. É só quando o seu bom comportamento é resultado de autocontrole, do que muitas vezes se denomina conflito ético ou moral, é que tem probabilidade de ser admirado (SKINNER, 1972, p. 182).

Para Skinner, os comportamentos considerados éticos, que deveriam ser aprendidos, precisariam ser continuamente reforçados, a ponto de acarretar a existência de um tipo de autocontrole que suscitaria a admiração dos outros agentes educacionais, reforçando positivamente a possibilidade de que tal atitude se tornasse frequente. As punições concernentes ao mau comportamento não seriam eliminadas, mas sua eficácia em produzir consequências desejadas seria menor que a da fomentada pela aplicação de reforços positivos. Diante desse quadro, a submissão da ética à lógica do reforço e/ou da punição obviamente remete à seguinte reflexão: e se finalmente houvesse uma máquina capaz de elaborar juízos morais que seriam utilizados pelos professores para avaliar comportamentos dos alunos? Skinner (1972, p. 248), ao afirmar, na última frase de seu livro "Tecnologia do ensino", que "o governo do futuro provavelmente funcionará principalmente através de técnicas educacionais", estaria também pensando nessa possibilidade da ética e dos juízos de valores serem maquinalmente formulados? 


\section{Dispositivos de decisão diretiva, aprendizagem profunda e ética rasa}

Máquinas capazes de elaborar juízos morais fazem parte de um contexto social no qual cada vez mais se consolidam os princípios da denominada IA. Criado em 1956 por um grupo de cientistas que participaram de um seminário ocorrido no Dartmouth College em Hanover, New Hampshire, nos EUA, cujo destaque foi a participação do pesquisador John McCarthy (1927-2011), o termo Inteligência Artificial foi elaborado por meio da premissa de que elementos dos processos de aprendizagem, ou de quaisquer características envolvidas em processos considerados inteligentes, poderiam ser maquinalmente simulados. Dentre uma miríade de definições referentes ao conceito de IA, poderia ser destacada a seguinte:

A inteligência artificial refere-se a um campo de conhecimento associado à linguagem, à inteligência, ao raciocínio, à aprendizagem e à resolução de problemas. A IA propicia a simbiose entre o humano e a máquina ao acoplar sistemas inteligentes artificiais ao corpo humano (prótese cerebral, braço biônico, células artificiais, joelho inteligente e similares) e a interação entre o homem e a máquina como duas espécies distintas conectadas (homens-aplicativos, homens-algoritmos de IA). [...]. Os estágios de desenvolvimento bem como as expectativas variam entre os campos e suas aplicações, que incluem veículos autônomos, reconhecimento de voz, games, robótica, tradução de linguagem natural, diagnósticos médicos, assim por diante. Atualmente, os sistemas inteligentes estão em todas as áreas do conhecimento (e quase em toda a vida em sociedade) (KAUFMAN, 2019, p. 19-20).

De acordo com essa definição, a simbiose homem-máquina, possibilitada pela IA, ocorre tanto na esfera somática quanto na mental. Na somática, é chegado o tempo dos membros biônicos, que são acoplados ao corpo humano gerando o conceito de seres humanos aumentados, e das nanocélulas artificialmente produzidas, que são utilizadas para, entre outras coisas, penetrar em tumores, de tal modo que suas células são explodidas sem que as saudáveis sejam prejudicadas. Já na esfera mental, a simbiose homem-máquina pode ser identificada nos chamados homens-aplicativos e homens-algoritmos. Os homensaplicativos e os homens-algoritmos coadunam-se ao modo de operação da lógica algorítmica dos mais variados tipos de aplicativos computacionais. Segundo Pierro (2018, p. 19), o algoritmo digital pode ser definido como uma "sequência 
lógica de passos para resolver um problema, que é escrita em linguagem de programação de computador". Assim, são definidas as etapas de realização de certos objetivos, ou seja, a sequência lógica de passos, cujos incontáveis dados e informações são convertidos em linguagem de programação de computador, de tal forma que se realizam as tomadas de decisões algorítmicas.

De fato, a utilização dos aplicativos se intensifica cada vez mais e se faz atualmente presente em praticamente todas as relações humanas, relações estas que são espacial e temporalmente modificadas. As modificações espaçotemporais são feitas por meio da atuação dos códigos computacionais dos programas de computadores, cujos softwares aplicativos são empregados para a resolução de questões práticas vinculadas ao processamento de dados. No caso do espaço de check-in de uma companhia aérea num determinado aeroporto, a presença de um software aplicativo de análise e processamento de dados é tão determinante para a realização de tais operações que, se houver algum tipo de pane, o próprio espaço como que deixa de existir. Ou seja, neste caso, a própria espacialidade é definida por meio da atuação do código computacional (KITCHIN; DODGE, 2011).

Mas não só os parâmetros espaciais se modificam na sociedade da comunicação e da conexão ubíquas, pois também a temporalidade é radicalmente transformada. Sobretudo após a propagação dos aparelhos celulares, que se tornaram uma espécie de computadores de bolso, nota-se a forma como as expectativas de conexão não mais possuem quaisquer limites temporais para que possam ser concretizadas. Em muitas ocasiões, se uma pessoa não responde imediatamente uma mensagem visualizada através do aplicativo WhatsApp, esta atitude é majoritariamente interpretada como falta de respeito ou consideração pela pessoa que a enviou.

A ausência de fronteiras espaçotemporais nos processos comunicacionais computacionalmente codificados não pode ser circunscrita exclusivamente à esfera do livre-arbítrio do indivíduo, que decidiria quando e onde responder a determinada demanda recebida por seus atuais gadgets eletrônicos. É todo um sistema de relações de produção, regulado pelos ditames do atual modo de produção capitalista, que alavanca o processo de desregulação ilustrado principalmente pela fissura entre as fronteiras das esferas pública e privada. Habermas já havia enfatizado o modo como mudanças estruturais na esfera pública se consumaram na sociedade do século $\mathrm{XX}$, sobretudo quando a propaganda se tornou uma mediação decisiva para essas mudanças através da utilização frenética dos meios de comunicação de massa, tais como o rádio, o cinema e, principalmente, a televisão. A partir do momento em que os indivíduos vão se tornando propagandas de si mesmos, o próprio "espaço social das decisões privadas é prejudicado por fatores objetivos como o poder de compra e a participação em grupos, sobretudo pelo status socioeconômico" (HABERMAS, 1984, p. 209). 
Em outro contexto, Adorno (1995) também refletiu sobre o declínio das fronteiras entre as esferas pública e privada, ao observar que a lógica das atividades do tempo livre se assemelhava, e muito, à das operações padronizadas das relações de trabalho. Ao invés de serem identificadas como uma espécie de refúgio do imediatismo e da vida e, portanto, completamente sujeitas ao exercício do livre-arbítrio dos indivíduos, as atividades do tempo livre, em sua maioria, eram subsumidas ao ethos das relações de trabalho. Dessa forma, havia um tipo de semelhança entre as sequências padronizadas dos filmes de ação de sucesso e as mesmas operações mecanizadas que o indivíduo teria que fazer em seu trabalho, sendo que tal simetria entre trabalho e tempo livre foi satirizada pela mímica magistral dos gestos mecanizados que Charlie Chaplin (1889-1977) executou no filme Tempos modernos.

Porém, nos tempos modernos da cultura digital, a consubstanciação entre as esferas pública e privada se consolida num ritmo tão acelerado que, provavelmente, impactaria até mesmo as maneiras como Adorno e Habermas elaborariam suas análises. Atualmente, se o docente universitário não responde imediatamente a um convite para publicar um artigo num dossiê de um periódico científico, ou então para proferir uma palestra, ele ou ela correrá o sério risco de ser substituído(a) imediatamente por outros docentes; se o confeiteiro(a) se recusa a responder a um pedido feito pelo WhatsApp (por exemplo, às 23 horas e 50 minutos, tratando-se de um horário fora de seu expediente de trabalho) de preparação de um bolo, então ele ou ela provavelmente também será excluído(a) e substituído(a) por alguém que se prontifique a atender a demanda do cliente naquele horário, mesmo sendo quase que de madrugada.

São, portanto, incontáveis os exemplos do modo como as esferas pública e privada se imiscuem na sociedade da conexão ubíqua. $\mathrm{O}$ atual solapamento de qualquer tipo de barreira entre estas esferas torna-se decisivo para que quantidades colossais de informações sejam selecionadas, classificadas e ordenadas, por meio dos algoritmos dos mecanismos de busca do Google, por exemplo, com os mais variados objetivos. O que de fato interessa é que massas gigantescas de dados continuem a ser produzidas para que possam ser utilizadas para os mais variados fins, sobretudo os de ordem econômica.

Evidentemente, fronteiras entre tais esferas poderiam obstaculizar não somente a geração de uma maior produção, como também o acesso aos dados informacionais. Justamente a ausência de tais barreiras impulsiona o desenvolvimento cada vez maior da chamada aprendizagem profunda (deep learning), que é assim definida: 
Deep learning é sobre previsão e permeia grande parte das atividades do século XXI. Quando digitamos uma consulta ao Google, é ele que seleciona a resposta personalizada e os anúncios apropriados ao perfil do usuário, bem como traduz um texto de outro idioma, assim como filtra os e-mails não solicitados (Spam). [...]. Quando acessamos um dispositivo computacional, em qualquer de seus formatos, provavelmente estamos acessando concomitantemente um processo de deep learning. $\mathrm{O}$ atual crescimento exponencial de dados inviabiliza o uso da tradicional programação computacional (com regras definidas a priori); a vantagem dos sistemas de aprendizado é que eles próprios estabelecem os algoritmos, i. e., adaptam-se automaticamente aos requisitos da tarefa (KAUFMAN, 2019, p. 25).

Gigantes da comunicação, tais como Amazon, Netflix e Spotify, recomendam livros, filmes e músicas por meio desse processo de aprendizagem profunda, cujos algoritmos como que "aprendem" cada vez mais, mediante a análise dos dados coletados, e se reprogramam para prever quais serão os possíveis perfis dos consumidores de tais produtos. Nesse processo, as causalidades são cada vez mais subordinadas às correlações estabelecidas entre os dados.

Ainda que em outro cenário histórico, realiza-se, de certa forma, o desejo positivista de Auguste Comte (1798-1857) de que as causas dos fenômenos históricos deveriam ser desconsideradas pelo cientista positivista, mediante o argumento de que seu estudo poderia acarretar controvérsias insuperáveis. Para Comte (1991), seria bem mais produtivo e eficiente caso fossem investigadas as correlações dos fenômenos estudados com o intuito de que fossem, posteriormente, concebidas as leis gerais referentes aos processos de produção e reprodução de tais fenômenos. Seguindo essa linha de raciocínio, o aprendizado profundo das correlações dos grandes dados (big data), continuamente amealhados em detrimento da investigação das causas e dos motivos pelos quais estes são produzidos e reproduzidos, faz com que mecanismos de gerenciamento e controle de contingências comportamentais, para se fazer uso da expressão de Skinner, tornem-se tão atuantes que cada vez menos provocam reações de estranhamento nos próprios indivíduos que os produzem. Deste modo, "programar significa capturar e ordenar conhecimento sobre o mundo - práticas, ideias, medidas, localizações, equações e imagens com o objetivo de aumentar, mediar e regular a vida das pessoas" (KITCHIN; DODGE, 2011, p. 26, tradução nossa). 
A programação compreendida como uma atividade de controle, principalmente dos indivíduos compreendidos como consumidores, é característica do capitalismo de vigilância, tal como foi denominado por Zuboff (2019). Embora a atitude de vigiar já estivesse presente há tempos no capitalismo - pensemos na vigilância das etapas das jornadas de trabalho dos operários nas fábricas e no exemplo do panóptico -, no atual modo de produção capitalista, vigiar se transforma em algo imprescindível para a esfera produtiva de forma inaudita. Vigiar o modo como os grandes dados (big data) são extraídos e classificados torna-se crucial para as atuais transações econômicas, assim como para todo o mercado incrivelmente promissor dos produtos que se comunicam entre si por meio da tecnologia da Internet das coisas (Internet of Things - IoT). Desde os já citados carros autônomos e nanopartículas, passando pelos drones e dispositivos vestíveis, desenvolve-se cada vez mais a tecnologia IoT, que faz com que as instalações de sensores em quaisquer objetos conectados à Internet permitam gerar "uma nova infraestrutura inteligente para corpos e objetos" (ZUBOFF, 2018, p. 27). Desta forma, a quantidade incomensurável de dados flui também de bancos governamentais e corporativos, bem como da coleta de informações de "câmeras de vigilância públicas e privadas, incluindo qualquer coisa desde smartphones até satélites, do Google Street View ao Google Earth" (ZUBOFF, 2018, p. 28).

No novo admirável mundo, no qual a obtenção, seleção, classificação e ordenação de dados determina a forma como quaisquer tipos de commodities são comercializadas, a vigilância ubíqua desmaterializa-se em relação à figura do panóptico, tal como foi idealizada por Jeremy Bentham (1748-1832), haja vista o fato de que não mais se faz necessário um centro físico de vigilância e de controle representado pelas torres das penitenciárias que possibilitavam a visão de todas as celas, situadas ao seu redor, no final do século XVIII.

$\mathrm{Na}$ sociedade da cultura digital do século XXI, a vigilância se espraia de uma tal forma em todas as relações humanas, bem como nas relações entre seres humanos e objetos, que se torna elemento fulcral para a produção e reprodução das mercadorias do capitalismo hodierno. Exatamente nesta sociedade, na qual a velocidade da obtenção e de comunicação de um dado pode implicar o sucesso ou o fracasso imediato de transações de quaisquer ordens, a maneira como a intervenção humana se concretiza, espaço e temporalmente, deixa muito a desejar em comparação com a velocidade e a precisão das tomadas de decisões das máquinas artificialmente inteligentes. Diante desse quadro, intensificam-se os investimentos de capital para o aprimoramento de computadores identificados como aparelhos de decisão diretiva (directive decision devices), cujos propósitos são descritos da seguinte forma: 
Possibilitar a substituição de funcionários humanos por artefatos computacionais centrados nos interesses variados de consistência, economia e objetividade [...] e estender o alcance administrativo efetivo (ou período de controle) daqueles que estão no ápice das hierarquias organizacionais. Dessa maneira, por mais problemático que seja, os dispositivos de decisão diretiva podem propiciar o uso da automação a serviço da autocracia (SUTHERLAND, 2008, p. 1069).

Os investimentos maciços de capital em relação ao desenvolvimento de tais dispositivos computacionais demonstram o modo como o ethos do capitalismo de vigilância se materializa nas decisões autocráticas subsidiadas pelo julgamento dos algoritmos dessas máquinas. É no capitalismo de vigilância que a IA poderá enfim se tornar um meio de cognição relativo aos meios de produção digitalmente produzidos e reproduzidos. É nessa conjuntura social que a própria condição ontológica do indivíduo é redefinida, haja vista o fato de que "você é a sua informação" (FLORIDI, 2005, tradução nossa). Sendo assim, se o capitalismo de vigilância apropriar-se cada vez mais dessa privacidade informacional, como parece ser a tendência dominante, então as próprias "capacidades primordiais da força de trabalho - cognição e percepção - serão remodeladas em formas maquinais adequadas ao capital" (DYER-WITHEFORD; KJOSEN; STEINHOFF, 2019, p. 62, tradução nossa).

Já de acordo com Sutherland (2008), além das vantagens econômicas derivadas do uso de tais aparelhos, uma vez que os custos operacionais se tornam mais baratos em comparação com os gastos implicados na manutenção da força humana de trabalho, há que se ressaltar a estandardização de tais decisões quanto às mais variadas atividades, tais como a escolha de um procedimento médico e até mesmo o controle algorítmico das luzes de semáforos. Por fim, há que se observar a padronização referente às decisões, que permite fazer com que a deliberação algorítmica elimine a suposta falibilidade humana subjetiva, de tal maneira que a "autoridade decisiva, relativa às decisões de aceite ou de rejeição, se torne prerrogativa da orientação algorítmica" (SUTHERLAND, 2008, p. 1081, tradução nossa). Tendencialmente, pode-se asseverar que as consequências da padronização algorítmica estão já implicando a produção de uma espécie de automação de comportamentos sociais, à medida que

uma miríade de pensamentos, gostos, emoções, confidências a amigos, declarações de amor, preferências sexuais, encontros amorosos, compras e vendas, adesões ideológicas, entre outros aspectos, torna-se atualmente objeto de mediações de plataformas on-line, serviços e aplicações (FORTUNATI, 2018, p. 2684, tradução nossa). 
A aplicabilidade de tais princípios, referentes aos usos de dispositivos de decisão diretiva, está se espraiando também para a esfera educacional, o que pode, num futuro muito próximo, transformar radicalmente as relações entre professores e alunos. Atualmente, já há softwares cujos algoritmos permitem fazer com que ocorra o reconhecimento das faces dos alunos, de tal modo que os professores recebem em seus smartphones a análise algorítmica dos vários tipos de comportamentos de seus alunos (WILLIANSON, 2017). Ou seja, a pretensão é a de que os julgamentos morais feitos por educadoras e educadores de seus alunos e alunas sejam condicionados numa tal medida que a tão propalada falibilidade humana será finalmente subjugada à estandardização atinente às decisões dos algoritmos digitais. E se o corpo docente se exime da responsabilidade de dialogar com as alunas e alunos sobre a forma como as mediações tecnológicas reconfiguram, por assim dizer, suas próprias relações dentro e fora da sala de aula, então as consequências para o processo formativo serão ainda mais prejudiciais, conforme concluem Finn e Ledbetter (2013) em suas pesquisas sobre a credibilidade docente decorrente do modo como as tecnologias digitais são ou não utilizadas no transcorrer das etapas do processo de ensino e aprendizagem. Esta posição sobre possíveis danos no processo formativo também é compartilhada por Edwards (2015), à medida que ele observa que a própria credibilidade das informações digitalmente obtidas advém da forma como essas se tornam ou não visíveis, de acordo com as decisões tomadas pelas professoras e professores.

Ora, os julgamentos morais das professoras e professores em relação aos comportamentos de suas alunas e alunos historicamente sempre se fizeram presentes nas relações estabelecidas entre eles. Os textos de Pierre Bourdieu (1930-2002) se notabilizaram, entre outros aspectos, pela forma como ele identificou a relevância desses julgamentos, notadamente em relação às avaliações das alunas e dos alunos franceses. Numa pesquisa sobre os julgamentos professorais de um grupo de alunas francesas, Bourdieu afirmou que as apreciações eram "tanto mais severas e mais brutalmente expressas, menos eufemísticas, quanto mais baixa é a origem social das alunas" (BOURDIEU, 2007, p. 192). Mas o que pensar sobre a configuração, fazendo-se uso de uma expressão maquinal, do julgamento das professoras e dos professores estabelecida pela logística de cálculo algorítmica dos softwares de reconhecimento facial? E o que Skinner diria sobre essa máquina de ensinar da cultura digital?

Talvez a resposta para ambas as questões seja a de que, na sociedade do capitalismo de vigilância, também os julgamentos morais e, de certa forma, a própria elaboração da consciência moral dos agentes educacionais tendam a se subsumir à autoridade algorítmica dos dispositivos de decisão diretiva. Assim, 
prevaleceria um sistema de premiação e punição que faria com que não apenas a dimensão cognitiva lhe fosse subsumida, como também a própria ética. Em nome da eficiência absoluta, a tecnologia digital poderia então finalmente amalgamar, nas salas de aula, as dimensões da ética e da cognição, que Skinner havia apartado como responsabilidades da professora e da máquina de ensinar, respectivamente. Já em tempos de cultura digital, ao receber os julgamentos morais em seus smartphones, por meio dos aplicativos dos softwares de reconhecimento facial, as professoras e professores poderiam então padronizar o modo como esse juízo impingiria diferentes tipos de avaliações morais do alunado.

Contudo, que tipo de relação de ensino e aprendizagem acontece quando professoras e professores deixam de ser figuras de referência para o corpo discente dessa maneira insólita? Provavelmente, a resposta para uma pergunta como esta implique refletir como o conceito de semiformação é revitalizado em tempos da hegemonia da cultura digital. Ao comparar a experiência formativa com a semiformação, Adorno elaborou as seguintes considerações:

A experiência - a continuidade da consciência em que perdura o ainda não existente e em que o exercício e a associação fundamentam uma tradição no indivíduo - fica substituída por um estado informativo pontual, desconectado, intercambiável e efêmero, e que se sabe que ficará borrado no próximo instante por outras informações [...]. A semiformação é uma fraqueza em relação ao tempo, à memória, única mediação capaz de fazer na consciência aquela síntese da experiência que caracterizou a formação cultural em outros tempos (ADORNO, 2010, p. 33).

Nessa citação, Adorno ressalta a diferença entre os elementos da experiência formativa e da semiformação, sobretudo em relação ao tempo e à memória. Quando ocorre a experiência formativa, há uma espécie de conjunção espaçotemporal entre o futuro (o ainda não existente) e o passado que faz com que o indivíduo elabore conceitualmente, em seu tempo presente, a relação que estabelece entre sua constituição identitária e a do coletivo do qual participa. Já em relação à semiformação, sobressai-se o imperativo do estado informativo pontual, de modo que a fragmentação dos dados, derivada do processo de disjunção espaçotemporal (como se o passado, o presente e futuro não mais dialogassem entre si), propicia um terreno fértil para vicejar o pensamento estereotipado e afeito ao preconceito, tal como Adorno conceituou na forma da mentalidade do ticket (ADORNO, 1972). 
A atribuição de rótulos ao indivíduo, que divide e etiqueta as pessoas como insiders ou outsiders, como dentro ou fora de seu grupo, demarcou as características das personalidades autoritárias na sociedade estadunidense da década de 1940 (ADORNO, 1972). Já na sociedade da cultura digital, a nova mentalidade do ticket é digitalmente revigorada pela lógica binária $0 / 1$ dos algoritmos que apresentam os rótulos dos julgamentos morais provenientes dos cálculos dos aplicativos dos dispositivos de decisão diretiva de reconhecimento facial.

Se prevalecer um processo de atribuição de reforço ou punição algoritmicamente calculado pelos softwares de tais dispositivos, que tipo de aprendizagem profunda poderia ser fomentada, principalmente se tais correlações algorítmicas entre os perfis dos(as) alunos(as) e os julgamentos morais sobrepujarem o entendimento das causas, das mediações históricas que determinam as idiossincrasias das relações estabelecidas entre os agentes educacionais? Será que, finalmente, as autoridades da professora e do professor se sujeitarão à autoridade algorítmica digitalmente configurada?

\section{Conclusão}

Historicamente, as professoras e os professores se destacaram como figuras de referência para as alunas e alunos. A despeito das divergências, sobretudo de ordem didática, entre as denominadas pedagogias humanista tradicional e moderna, os membros do corpo docente sempre se caracterizaram como elementos fundamentais, como referências em relação ao processo de desenvolvimento das capacidades cognitivas das alunas e alunos, e de suas respectivas consciências morais.

Um olhar enviesado ou um sorriso de satisfação diante das respostas das alunas e alunos sobre determinada questão, entre outras reações, sempre exerceu um papel decisivo em relação ao modo como elas e eles se sentiram motivados a refletir e, literalmente, incorporar as informações para que estas pudessem ser transformadas em conceitos e, portanto, em conhecimento. Com efeito, as características das personalidades das educadoras e educadores sempre foram identificadas como elementos determinantes da própria dimensão formativa, a ponto de Freud (1856-1939) admitir o seguinte: "é difícil dizer se o que exerceu mais influência sobre nós e teve importância maior foi a nossa preocupação pelas ciências que nos eram ensinadas, ou pela personalidade de nossos mestres" (FREUD, 1976, p. 1). Se as personalidades das professoras e dos professores sempre foram tão relevantes para as alunas e alunos a ponto 
de suas idiossincrasias pessoais influenciarem decisivamente a forma do desenvolvimento das habilidades cognitivas das alunas e alunos, como elas e eles se sentiriam ao saber que suas educadoras e educadores submeteriam seus julgamentos aos juízos morais configurados pelos algoritmos dos softwares dos dispositivos de decisão diretiva?

Não há como negar, por um lado, os mais variados benefícios obtidos pelo uso do mecanismo de busca do Google, por exemplo. A obtenção das informações referentes a quaisquer tipos de demandas facilita qualquer tipo de trabalho de pesquisa que possa ser atualmente feito em relação a todas as áreas de conhecimento. Mas, por outro lado, não se pode desconsiderar o fato de que, em tempos da cultura digital, cujas operações de tais algoritmos permitem fazer com que se possa lembrar de tudo, novas formas de esquecimento são produzidas. Os esquecimentos ocorrem sobretudo quando as causas históricas, que determinaram as tonalidades da miríade de informações digitalmente obtidas, são obnubiladas revitalizando-se, historicamente, o conceito de semiformação elaborado por Adorno.

$\mathrm{O}$ acesso a tais informações não significa necessariamente que se desenvolverá a chamada formação cultural. Se essa formação se pautou no esforço espontâneo, que fazia com que as alunas e os alunos se sensibilizassem eticamente a ponto de aplicar em suas práticas cotidianas o que outrora haviam aprendido em sala de aula sobre o conceito de preconceito, por exemplo, não há como pensar que tal procedimento ético se tornaria uma consequência imediata decorrente da forma como a professora e o professor pune ou reforça os supostos comportamentos éticos do corpo discente, por meio da utilização dos dispositivos de decisão diretiva. Nesse momento, é interessante lembrar a concordância de Adorno em relação ao pensamento de Max Scheler (1874-1928) de que "havia obtido efeitos pedagógicos pelo fato de que nunca tratara seus alunos de maneira pedagógica" (ADORNO, 2000, p. 164).

Quando as professoras e os professores não se entregam ao sortilégio do julgamento algoritmicamente elaborado pelos dispositivos de decisão diretiva e, portanto, se recusam a convencer as alunas e alunos de que sempre têm razão, à medida que os convidam para dialogar sobre as informações estudadas para que sejam transformadas em conceitos, então há uma possibilidade de que a elaboração crítica das informações algoritmicamente obtidas realmente contribua para o efetivo aprofundamento da aprendizagem. Cada vez que as(os) educadoras(es) e alunas(os) utilizam as máquinas das tecnologias digitais de informação e comunicação para recuperarem imediatamente dados que, ao serem historicamente relacionados entre si, fomentam o surgimento de ponderações sobre as consequências de determinados comportamentos em relação a outros, 
então há uma possibilidade de que a reflexão ética não seja apartada da produção do próprio conhecimento (separação esta proposta por Skinner), mas sim identificada como algo que lhe é profundamente imanente.

Ou seja, a aprendizagem profunda é aquela que não se consubstancia com uma ética rasa assentada no sistema de premiações e punições do atual capitalismo de vigilância, cujo ethos também se faz presente nas salas de aula. Para que isso ocorra, as atitudes das professoras e professores, que assumem suas condições de seres humanos sujeitos a falhas e acertos, muito provavelmente suscitarão um tipo de empatia entre as alunas e alunos que fará com que ambos os grupos, enquanto agentes educacionais, utilizem as tecnologias digitais para compreender as causas dos fenômenos educacionais e se sensibilizar eticamente a mudar suas próprias práticas dentro e fora das escolas. Portanto, em tempos da digitalização da vida em suas mais variadas esferas, mais do que nunca as professoras e os professores continuam na moda.

\section{REFERÊNCIAS}

ADORNO, Theodor Wiesengrund et al. The Authoritarian Personality. Nova York: Harper, 1950.

ADORNO, Theodor Wiesengrund. Tempo livre. In: ADORNO, Theodor Wiesengrund. Palavras e sinais. Petrópolis: Vozes, 1995. p. 70-83.

ADORNO, Theodor Wiesengrund. Tabus a respeito do professor. In: ZUIN, Antônio; PUCCI, Bruno; RAMOS-DE-OLIVEIRA, Newton. Adorno: o poder educativo do pensamento crítico. 4. ed. Petrópolis: Vozes, 2000. p. 157-177.

ADORNO, Theodor Wiesengrund. As estrelas descem à Terra: a coluna de astrologia do Los Angeles Times: um estudo sobre superstição secundária. São Paulo: Editora Unesp, 2008.

ADORNO, Theodor Wiesengrund. Teoria da semiformação. In: PUCCI, Bruno; ZUIN, Antônio Alvaro Soares; LASTÓRIA, Luiz Antônio (org.). Teoria crítica e inconformismo: novas perspectivas de pesquisa. Campinas: Autores Associados, 2010. p. 7-41.

ANDERS, Günther. Die Antiquiertheit des Menschen I. München: C. H. Beck, 2002.

ARISTÓTELES. Ética a Nicômaco. São Paulo: Abril Cultural, 1991.

BOURDIEU, Pierre. As categorias do juízo professoral. In: NOGUEIRA, Maria Alice; CATANI, Afrânio (org.). Pierre Bourdieu: escritos de educação. Petrópolis: Vozes, 2007. p. 185-217. 
COMTE, Auguste. Discurso preliminar sobre o conjunto do positivismo. São Paulo: Nova Cultural, 1991. (Coleção Os pensadores).

DICK, Philip. Electric dreams: sonhos elétricos. São Paulo: Aleph, 2018.

DYER-WITHEFORD, Nick; KJOSEN, Atle Mikkola; STEINHOFF, James. Inhuman power: artificial intelligence and the future of capitalism. London: Pluto Press, 2019.

EDWARDS, Richard. Software and the hidden curriculum in digital education. Pedagogy, Culture \& Society, London, v. 23, n. 2, p. 265-279, 2015.

FINN, Amber; LEDBETTER, Andrew. Teacher power mediates the effects of technology policies on teacher credibility. Communication Education, [S.l.], v. 61, n. 1, p. 26-47, 2013.

FLORIDI, Luciano. The ontological interpretation of informational privacy. Ethics and Information Technology, [S.l.], v. 7, p. 185-200, 2005.

FORTUNATI, Leopoldina. Robotization and the domestic sphere. New Media \& Society, Chicago, v. 20, n. 8, p. 2673-2690, 2018.

FREUD, Sigmund. Algumas reflexões sobre a psicologia escolar. Rio de Janeiro: Imago, 1976. (Edição brasileira das obras psicológicas completas de Sigmund Freud, v. xiii).

HABERMAS, Jürgen. Mudança estrutural da esfera pública: investigações quanto a uma categoria da sociedade burguesa. Rio de Janeiro: Tempo Brasileiro, 1984.

HUXLEY, Aldous. Admirável mundo novo. Rio de Janeiro: Cia. Brasileira de Divulgação do Livro, 1969.

KAUFMAN, Dora. A inteligência artificial irá suplantar a inteligência humana? São Paulo: Estação das Letras e Cores, 2019.

KITCHIN, Rob; DODGE, Martin. Code/Space: software and everyday life. Cambridge/ London: Mit Press, 2011.

PIERRO, Bruno. O mundo mediado por algoritmos. Pesquisa Fapesp, São Paulo, ed. 266, p. 18-25, abr. 2018.

SKINNER, Burrhus Frederic. Tecnologia do ensino. São Paulo: Editora Pedagógica e Universitária, 1972.

SUTHERLAND, John. Directive decision devices: reversing the locus of authority in human-computer associations. Technological Forecasting \& Social Change, [S.l.], v. 75, n. 7, p. 1068-1089, 2008.

TÜRCKE, Christoph. Hiperativos! Abaixo a cultura do déficit de atenção. Rio de Janeiro: Paz e Terra, 2016.

WILLIANSON, Ben. Moulding student emotions through computational psychology: affective learning technologies and algorithmic governance. Educational Media International, [S.l.], v. 54, n. 4, p. 267-288, 2017. 
ZUBOFF, Shoshana. Big other: capitalismo de vigilância e perspectivas para uma civilização de informação. In: BRUNO, Fernanda et al. Tecnopolíticas da vigilância: perspectivas da margem. São Paulo: Boitempo, 2018. p. 17-69.

ZUBOFF, Shoshana. The age of surveillance capitalism: the fight for a human future at the new frontier of power. London: Profile Books, 2019.

Texto recebido em 22/03/2021.

Texto aprovado em 09/04/2021. 